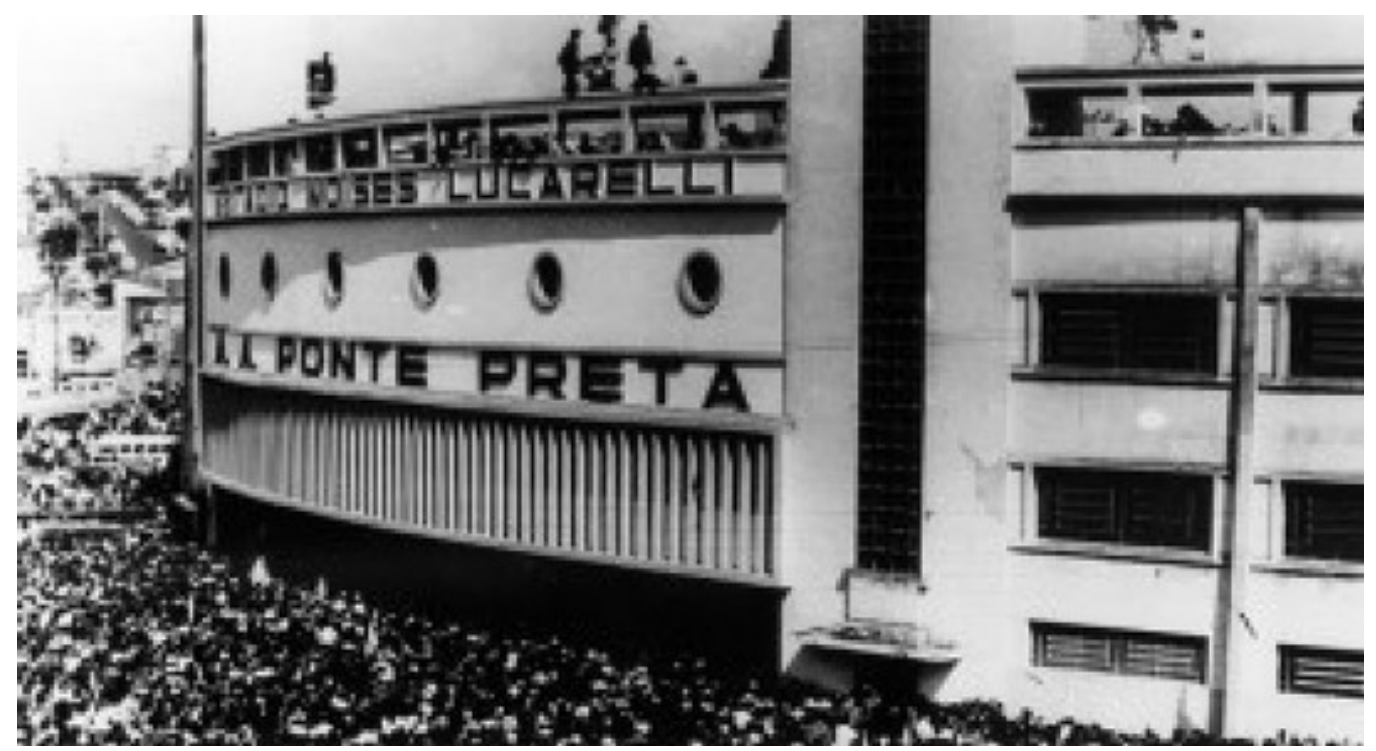

A patrimonialização do cotidiano: desafio para as políticas públicas

The diurnal heritage: challenges for public policies

Fabíola Rodrigues ${ }^{1}$

\title{
Resumo:
}

Esse artigo tenciona discutir as escolhas técnicas e políticas envolvidas no processo de patrimonialização de bens de interesse cultural. Para tanto, o presente texto busca resgatar o processo de alargamento do conceito de patrimônio cultural na política de preservação adotada na cidade de Campinas, salientando o progressivo deslocamento da prática de proteção assentada no registro do patrimônio excepcional para o registro do patrimônio cotidiano.

Palavras-Chave: patrimônio cultural; políticas públicas; urbanização; memória social.

\begin{abstract}
:
This article aims to discuss the technical and political choices involved in the heritage of goods of cultural interest. To that end, this text seeks to rescue the process of extending the concept of cultural heritage preservation policy adopted in the city of Campinas, emphasizing the progressive protection practice displacement from the exceptional heritage to the diurnal heritage.
\end{abstract}

Keywords: cultural heritage; public policies; urbanization; social memory.

\footnotetext{
${ }^{1}$ Fabíola Rodrigues é bacharel em Ciências Sociais (UNICAMP), mestre e doutora em Demografia (UNICAMP), Especialista Cultural da Coordenadoria Setorial do Patrimônio Cultural (CSPC), da Secretaria Municipal de Cultura, da Prefeitura de Campinas. Email: fabiola rodrigue@yahoo.com.br Endereço postal: Rua Francisco Humberto Zuppi, 1252, Cidade Universitária, CEP: 13083-350, Campinas-SP
} 


\section{A patrimonialização do cotidiano: desafio para as políticas públicas}

Em reunião do dia 10 de março de 2011, o Conselho de Defesa do Patrimônio Cultural de Campinas (CONDEPACC) decidiu, após acalorada reunião, pela abertura de estudo de tombamento do estádio Moisés Lucarelli, pertencente à Associação Atlética Ponte Preta.

A singularidade desse ato administrativo - a abertura de estudo de tombamento do estádio Moisés Lucarelli - reside no interesse que ele despertou dentre os mais diversos segmentos da sociedade: os postulantes do pedido de abertura de estudo de tombamento (grupo ligado ao próprio clube), os oponentes do pedido (investidores imobiliários e credores, às vezes pertencentes ao próprio clube), conselheiros e também cidadãos anônimos, torcedores que enxergaram no tombamento a oportunidade de perpetuar a memória do clube, por meio da preservação do seu principal patrimônio, o "Majestoso".

Mas, afinal, de que memória estamos falando? Eis, então, que o elemento mais interessante dessa história nos aparece: o estádio Moisés Lucarelli, inaugurado em setembro de 1948, foi ao longo de vários anos construído pelos próprios torcedores, que doaram ao clube seu trabalho, seus recursos financeiros, seu tempo, seu engajamento num projeto comum: a sede própria.

A curiosidade, o interesse, as veementes manifestações de apoio e de repúdio à abertura do estudo de tombamento evidenciam, nesse sentido, um acontecimento surpreendente: a política patrimonial tocou a delicada epiderme de um monumento.

Nos termos precisos e sensíveis de Françoise Choay (2001), o monumento refere-se:

\footnotetext{
"àquilo que evoca a lembrança de alguma coisa. Para o monumento, a dimensão afetiva é fundamental (trata-se de tocar pela emoção uma memória viva) e a especificidade do monumento deve-se, exatamente, ao seu modo de atuação sobre a memória, à sua capacidade de invocá-la, de vibrá-la, de colocá-la em movimento. O monumento assegura, acalma, tranquiliza (...) Ele constitui uma garantia das origens e dissipa a inquietação gerada pela incerteza dos começos" (p. 18)
}

Propulsor dos afetos que põem em relação e dotam de significado os testemunhos da cultura material de um grupo ou segmento social específico, raramente o monumento afetivo coincide com o monumento histórico - este, selecionado da massa de bens existentes a partir do olhar informado da técnica e da ciência, mas que, frequentemente, passa ao largo das afeições populares. 
Essa constatação tem consequências interessantes: a política patrimonial em seu esforço de salvaguardar, conservar e preservar testemunhos relevantes da cultura material e, às vezes, imaterial de um determinado território, não raras vezes opera escolhas que reforçam clivagens sociais profundas preexistentes - no embate entre os testemunhos que documentam a excepcionalidade e aqueles que documentam a cotidianidade é quase certo que a força da excepcionalidade prevalecerá.

Para quem atua como policy maker da política patrimonial não é nada confortável enfrentar essas clivagens e, muitas vezes, ver-se presa nas poderosas armadilhas da parafernália teórico-metodológica empregada para justificar escolhas técnicas e políticas coalhadas de subjetividade. No entanto, mais difícil ainda, é, por vezes, enfrentar a estupefação e a incredulidade de outros "agentes do campo" quando nos propomos subverter as prioridades da política. Isso porque, afinal, a afetividade nas práticas patrimoniais é ainda "irmã bastarda" da arquitetura, que quase sempre pauta as decisões no que diz respeito às razões que orientam a preservação de bens de interesse cultural.

Inverter as prioridades da política é, quase sempre, sinônimo de questionar o reputado inabalável monopólio da arquitetura como elemento definidor do que merece e do que não merece ser preservado pelo instituto do tombamento - essa limitação ao direito de propriedade que conhecemos do direito português e que incorporamos ao nosso ordenamento jurídico a partir da edição do Decreto-Lei $n^{\circ} 25$, de 1937, que instituiu o Serviço do Patrimônio Histórico e Artístico Nacional (SPHAN).

É verdade que o próprio instituto do tombamento contribuiu para que a arquitetura fosse alçada à condição de substrato técnico e teórico da política patrimonial, uma vez que o registro no livro do tombo pressupunha, ao mesmo tempo, uma materialidade indiscutível e uma imutabilidade garantida por força da própria limitação ao direito (de uso) da propriedade.

No entanto, é interessante observar que mesmo quando não se trata do tombamento de um bem, mas, por exemplo, de um inventário com um recorte qualquer, da delimitação de uma área envoltória ou de uma simples listagem de bens de valor patrimonial, a arquitetura, o elevado valor estético, a distinção das formas e de estilos se impõem, imperativamente, como critério por excelência de escolha.

Essa constatação, é bom observar, não exprime um juízo antiarquitetônico ou uma defesa de boicote à arquitetura, mas se propõe lembrar que as lentes a partir das quais julgamos a realidade estão impregnadas pelas disputas sociais travadas em torno 
da construção do que é socialmente relevante - e é evidente que o apuro estilístico ou que o monumental valor estético de uma obra já expressam, per se, suas vinculações sociais, o seja, já enunciam os grupos sociais específicos e bem definidos que representam.

Nesse contexto, a questão fundamental a ser respondida é como escapar da armadilha da atribuição de significado aos bens patrimoniais, orientada por cânones estéticos e artísticos que, afinal, terminam por chancelar como socialmente legítimas e relevantes (em detrimento de outras) as expressões materiais dos grupos mais poderosos, política e economicamente dominantes?

A experiência da cidade de Campinas e de seu órgão de preservação, o CONDEPACC, provavelmente compondo uma trajetória semelhante a de tantos outros municípios e órgãos de defesa do patrimônio espalhados pelo país, mostra que a ampliação da abrangência social da política patrimonial passa, necessariamente, por um deslocamento da valoração da excepcionalidade (estética, arquitetônica, artística), para a valoração da cotidianidade (dos modos de fazer, de trabalhar, de produzir, de viver) como substrato das ações de preservação.

\section{As práticas patrimoniais em Campinas: o difícil deslocamento da excepcionalidade para a cotidianidade}

O Conselho de Defesa do Patrimônio Cultural de Campinas (CONDEPACC) foi instituído pela Lei $\mathrm{n}^{\mathrm{o}}$ 5.885, em 17 de dezembro de 1987, com o objetivo de assegurar a preservação do patrimônio cultural de interesse local.

É interessante observar que o órgão foi criado antes mesmo da emergência da Constituição Federal de 1988 no ordenamento jurídico brasileiro, antecipando-se, portanto, à legislação federal no reconhecimento do município como ente investido da competência de zelar pelo patrimônio cultural, no âmbito da repartição de competências entre os entes da federação (MEIRELLES, 2010)

Em Campinas, o primeiro tombamento do órgão municipal (CONDEPACC) destinado a salvaguardar um bem cultural em virtude de sua importância como "documento" do mundo do trabalho e da produção fabril - portanto, como espaço de práticas do cotidiano - foi o referente ao Complexo Ferroviário Central da FEPASA, 
sito à Praça Marechal Floriano Peixoto $s / n^{\circ}$ (Processo de Tombamento $n^{\circ}$ 04/1989; Resolução de Tombamento ${ }^{\circ}$ 004/1990).

Nesse tombamento, em que o bem protegido passou a ser tratado (ao menos, teoricamente) de uma perspectiva mais abrangente em virtude de suas características de complexo produtivo - em que pese a ainda sensível importância da relevância arquitetônica como critério de seleção dos edifícios protegidos pelo tombamento, em detrimento de uma leitura mais orgânica do bem, atenta às suas particularidades de planta produtiva (FRANCISCO, 2007) - o Colegiado de Campinas sinalizou para o reconhecimento formal da legitimidade dos testemunhos materiais do "mundo fabril" como passíveis de patrimonialização.

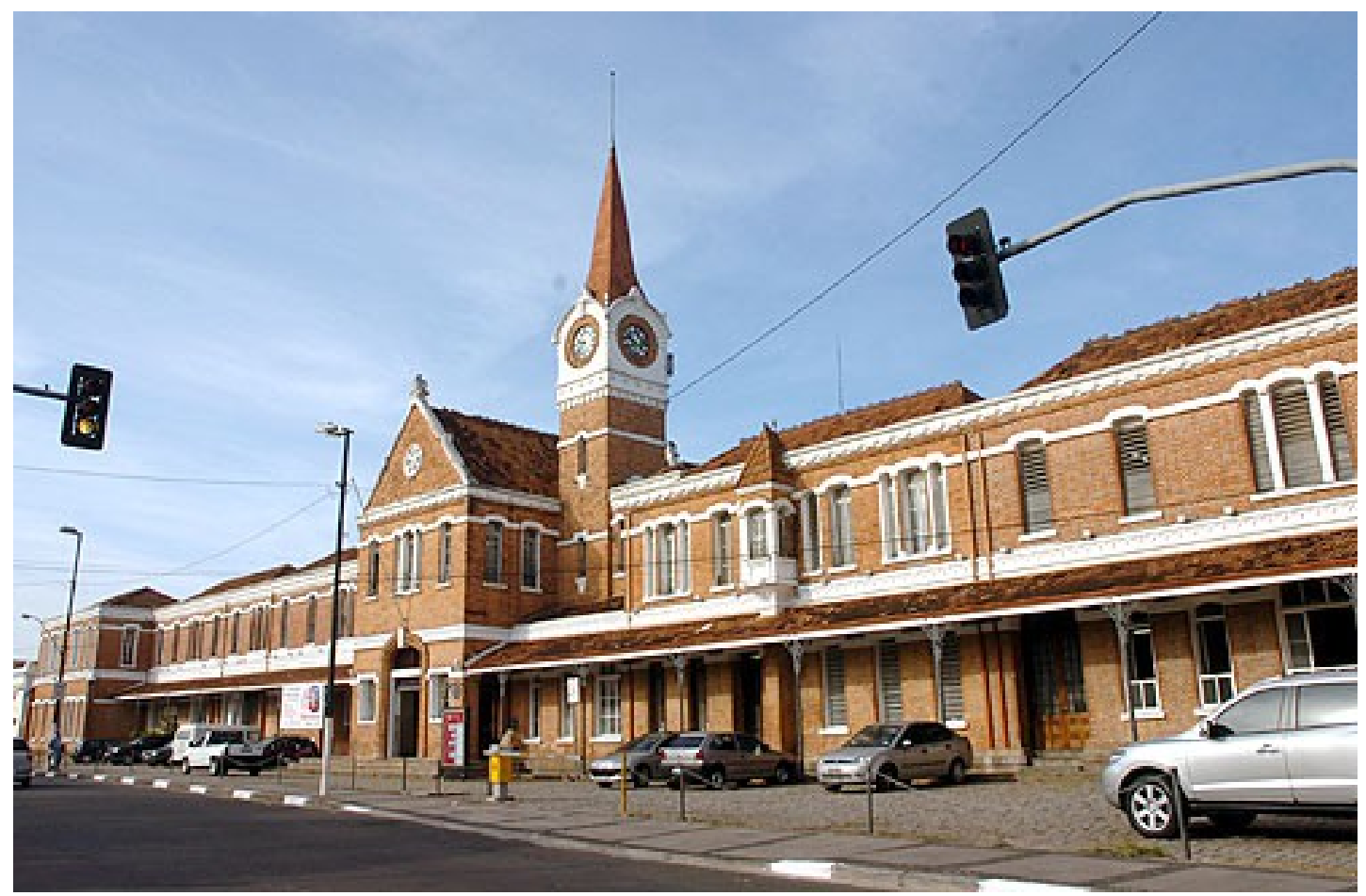

Figura 01. Estação Ferroviária da antiga Companhia Paulista (atual Estação Cultura) Fonte: Acervo da Coordenadoria Setorial do Patrimônio Cultural (CSPC), 2010.

Decorridos mais de vinte anos desse tombamento pioneiro, a prática patrimonial em Campinas ainda enfrenta dificuldades para avançar na preservação de edifícios não excepcionais, que interessam como bens culturais por sua importância como testemunhos ou suportes de técnicas, processos, ofícios, maquinários, ferramentas, ou ainda, por sua significação simbólica e afetiva para grupos sociais específicos, não raras vezes, socialmente modestos.

Essa constatação dá a medida da real dificuldade de se democratizar a política patrimonial, pois se o monumento histórico serve, justamente, de suporte à memória 
afetiva (CHOAY, 2001), uma política pública de preservação e gestão do patrimônio cultural deve se mostrar atenta e sensível à pluralidade de representações sociais e culturais, capaz de selecionar da massa de bens passíveis de preservação, existentes na paisagem, um conjunto de elementos consistente e representativo dos processos sociais, econômicos, políticos e culturais que dão inteligibilidade à (trans)formação da paisagem urbana.

Nesse sentido, o inventário das Vilas Operárias de Campinas, edificadas no período compreendido entre 1930-1960, atualmente em processo de construção pela equipe da Coordenadoria Setorial do Patrimônio Cultural (CSPC) - órgão de apoio técnico ao CONDEPACC - demonstra o esforço da política patrimonial em documentar e encampar os testemunhos da cultura material das camadas populares.

Se é verdade que o CONDEPACC já atentou para outros bens importantes que exprimem práticas e valores associados ao mundo do cotidiano e, sobremaneira, ao mundo do trabalho, como exemplificam o tombamento de edifícios industriais (Lidgerwood Manufacturing Ltda - Processo de Tombamento n ${ }^{\circ}$ 03/1989; Fábrica de Chapéus Cury - Processo de Tombamento n03/1994; Indústria de Seda Nacional Processo de Tombamento $\mathrm{n}^{\circ} 06 / 2009$ ), a grande novidade, eu diria ousadia, do supramencionado inventário das vilas operárias é, precisamente, marcar como passível de patrimonialização bens culturais que dificilmente seriam legitimados por sua arquitetura (de resto, "banal"), mas, que ganham sentido por seu valor afetivo, ou por seu caráter de documento do processo de urbanização por que passou a cidade.

Nesse contexto de "busca" pela democratização da prática e da política patrimoniais, um tombamento em especial - o da Torre do Castelo - chama a atenção como significativo da transição entre a salvaguarda de bens cuja preservação estava calcada na excepcionalidade - ou pelo menos na exemplaridade arquitetônica, e a preservação de bens culturais cujo substrato reside no seu caráter de suporte material de processos sociais variados, representativos de mudanças produtivas, tecnológicas, urbanísticas, ou simplesmente afetivas.

O processo de estudo de tombamento da Torre do Castelo foi, certamente, um dos primeiros a levar em consideração na motivação de sua abertura o conceito de paisagem cultural, tal como postulado na Carta de Bagé:

Art. $2^{\circ}$ - A paisagem cultural é o meio natural ao qual o ser humano imprimiu as marcas de suas ações e formas de expressão, resultando em uma soma de todos os resultantes da 
interação do homem com a natureza e, reciprocamente, da natureza com o homem, passíveis de leituras espaciais e temporais (CARTA DE BAGÉ, 2007).

Isso porque a área onde hoje se encontra a Torre do Castelo compunha uma antiga fazenda cafeeira, a Fazenda Chapadão, uma das primeiras na cidade a ser objeto de parcelamento e loteamento urbanos, em período contemporâneo à confecção do Plano de Melhoramentos Urbanos e à construção da caixa d'água-mirante popularmente conhecida como Torre do Castelo - que sintetizava suas pretensões modernistas.

De fato, a Torre do Castelo, de uma perspectiva puramente arquitetônica, é um edifício muito despojado, simples, com altura hoje relativamente insuficiente para cumprir com sua função de belvedere (há, mesmo no seu entorno mais imediato, edifícios com altura superior, que prejudicam a vista que o edifício oferece da cidade), mas cujo tombamento se amparou na extrema significação simbólica desse bem, que foi erguido como símbolo da modernidade que o Plano de Melhoramentos Urbanos (conhecido pela alcunha de "Plano Prestes Maia") pretendia conferir à cidade, dotandoa de avenidas largas, de trânsito rápidas, ciosamente planejadas, que já prenunciavam a primazia do automóvel, de seu ritmo e de suas necessidades na definição do desenho urbano (RIBEIRO, 2007; RODRIGUES, 2008).

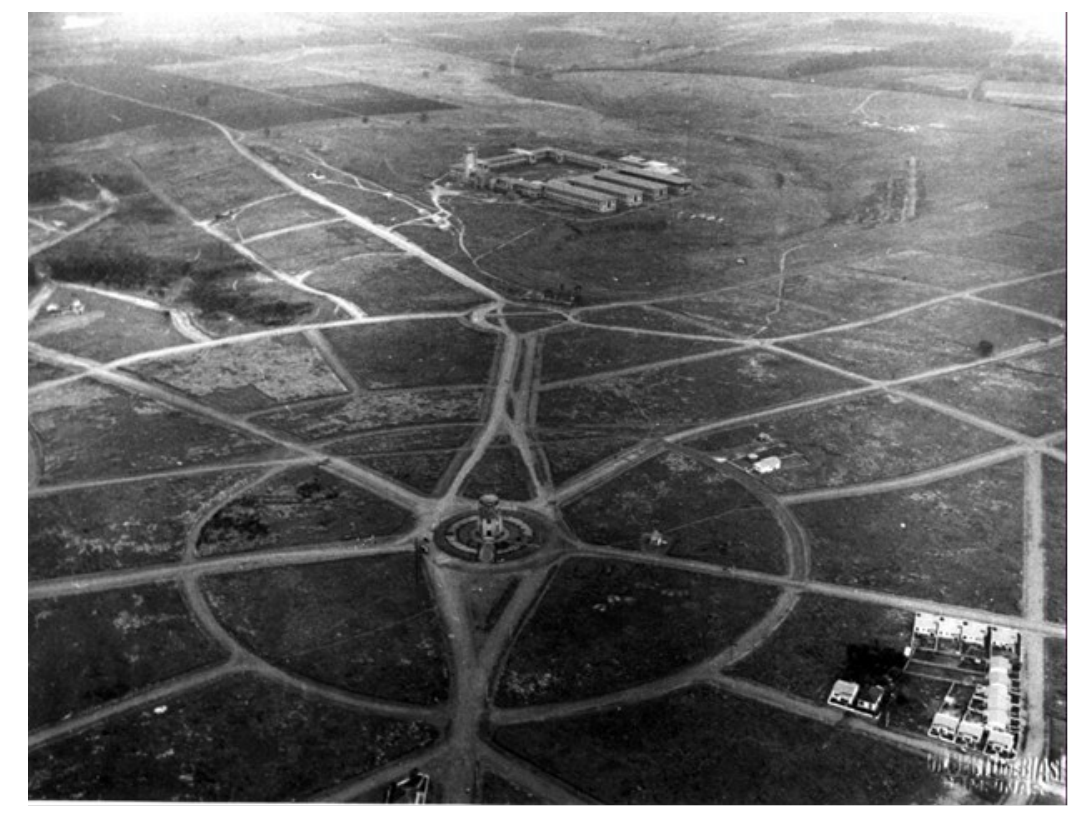

Figura 02. Vista aérea do Jardim Chapadão, vendo-se ao centro a Torre do Castelo e ao seu redor as diretrizes viárias propostas pelo Plano de Melhoramentos Urbanos. Fonte: Acervo da Biblioteca Municipal de Campinas, 2008.

O tombamento da Torre do Castelo é, pois, muito relevante, porque o mais importante na decisão da salvaguarda não foram as qualidades intrínsecas do edifício, 
mas sim sua significação simbólica, seu caráter de testemunho do processo de urbanização, de evolução da morfologia urbana, sua característica de documento do expressivo peso que o urbanismo assumiu no processo de modernização - conservador e excludente - vivenciado por Campinas na longa duração do Plano de Melhoramentos Urbanos (1938-1970).

Nessa mesma perspectiva, a moradia operária - até mesmo diferentemente dos edifícios industriais, que de modo geral se impõem na paisagem por seu grande volume (o que não raro os torna alvo da sanha imobiliária em áreas reputadas como adequadas à refuncionalização) - é pequena, modesta, de feições às vezes acanhadas, não possui um estilo arquitetônico que a identifique, caracterizando-se por sua "funcionalidade", ou seja, o programa de necessidades que, simplificado e econômico, quase sempre se repete: alpendre, sala, cozinha, dormitório(s).

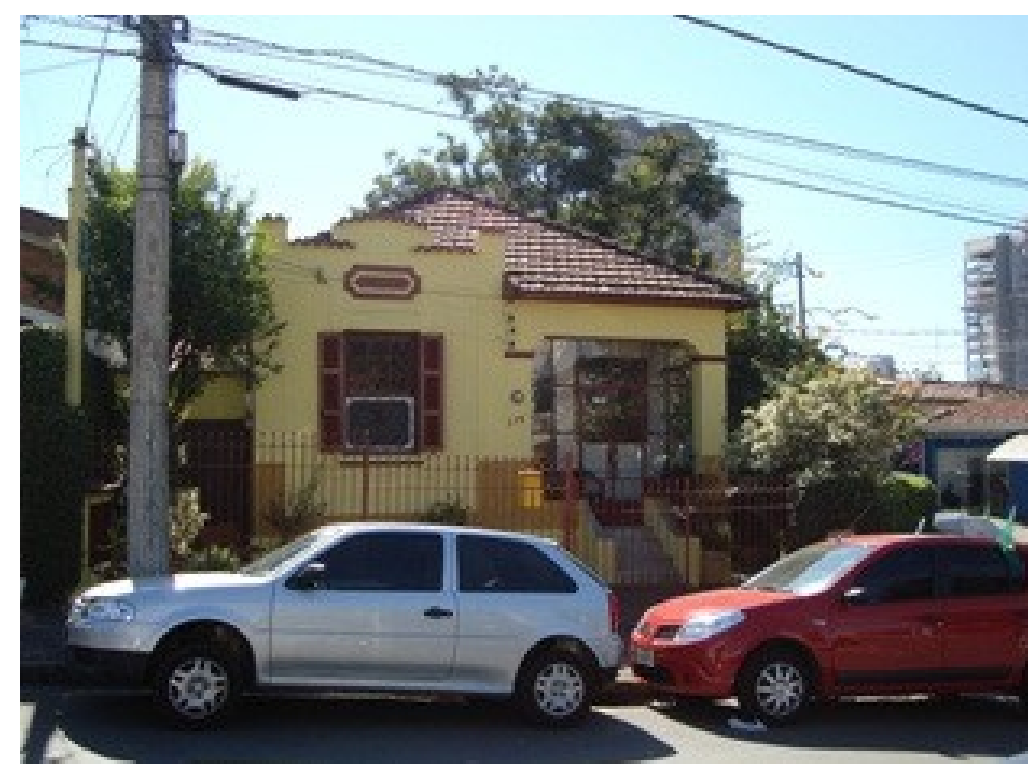

Figura 03. Imóvel sito à Rua Américo Brasiliense, no 379, localizado na Vila Almeida. Fonte: Acervo da CSPC. Levantamento de campo do projeto "Vilas Operárias (1930-1960)", 2010. 


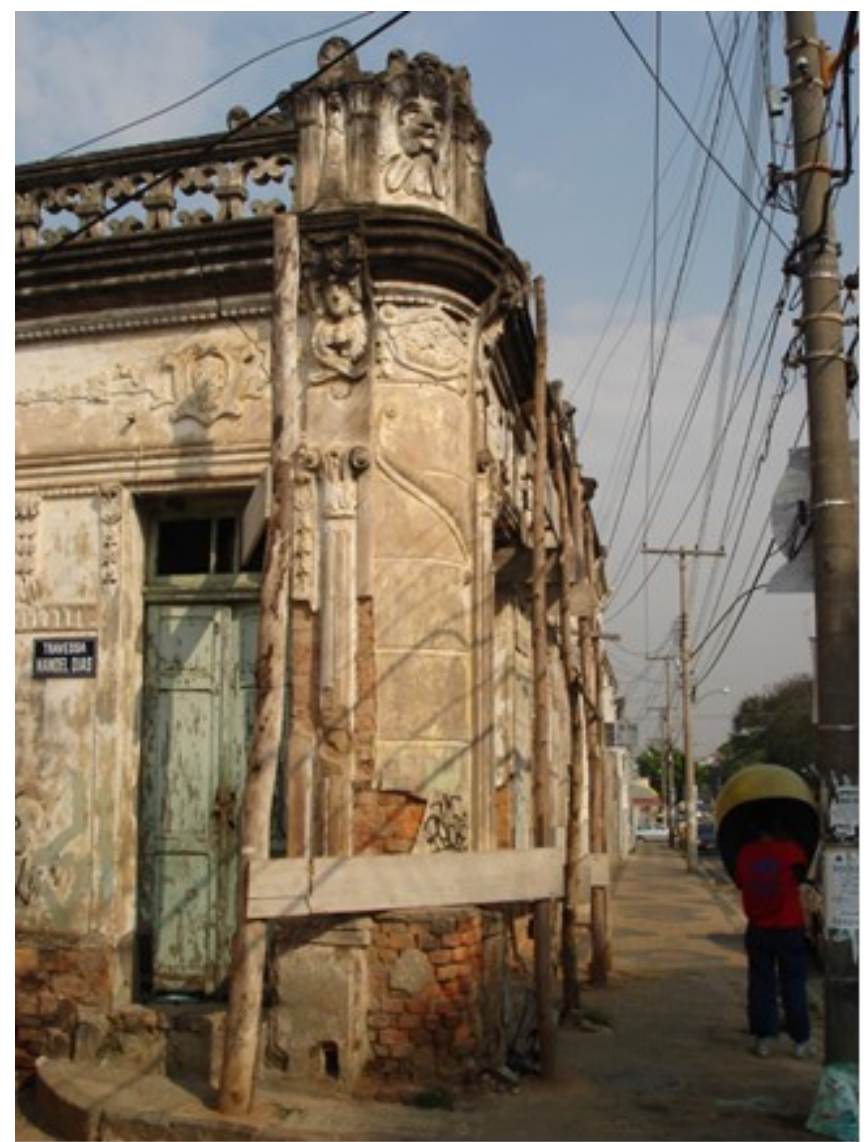

Figura 4: Imóvel da Vila Manoel Dias, escorado, já sob risco iminente de desabamento. Fonte: Acervo da CSPC, 2010.

Essa arquitetura "banal", encravada no espaço banal (SANTOS, 1999), inacreditável sobrevivente dos processos de destruição/reconstrução do tecido urbano, assume relevância por sua capacidade de testemunhar o modo de vida dos pobres; nesse sentido, sua salvaguarda torna possível uma espécie de "arqueologia da pobreza", pois seu registro sistemático e continuado no tempo permitirá recompor os intrincados processos de produção social do espaço urbano, calcados na permanente, contínua e radial expulsão da pobreza para as franjas longínquas, desvalorizadas e insalubres da cidade.

Nesse sentido, o inventário das vilas operárias, desenvolvido pela equipe técnica da Coordenadoria Setorial do Patrimônio Cultural (CSPC), lança luz sobre um fenômeno de dupla face: primeiramente, a identificação, o registro e a possível adoção de medidas de salvaguarda dos testemunhos materiais das camadas populares - em especial, de certos segmentos da classe trabalhadora, a exemplo dos ferroviários sinaliza para uma verdadeira democratização da política patrimonial, visto que incorpora no conjunto de bens passíveis de patrimonialização testemunhos materiais do modo de vida de grupos diferentes daqueles politica e economicamente mais 
importantes, legitimando seus artefatos culturais como relevantes para a memória social urbana.

Um segundo aspecto a ser considerado é que ao eleger a arquitetura não canônica e não excepcional das classes trabalhadoras, o inventário e seus possíveis resultados iluminam as características do modo de construir e de morar das camadas populares, realçando um aspecto da arquitetura frequentemente negligenciado pelas práticas patrimoniais, ou seja, sua condição de suporte material das formas de existir e de ocupar, produzir e reproduzir o espaço associados a determinado segmento social ou a certa temporalidade histórica.

Essas observações apontam para uma dimensão de "justiça social" que pode ser reputada à política patrimonial à medida que ela se compromete, verdadeiramente, com a proteção de bens culturais diversos que, mobilizando afetos e legitimando a significação simbólica dos artefatos culturais dos múltiplos grupos sociais em relação (e em disputa) no e pelo espaço urbano, tornam-se geradores ou reforçadores de vínculos de pertencimento de indivíduos e grupos com a própria cidade.

Nesse sentido, democratizar a política e as práticas de proteção e de gestão do patrimônio cultural importa, também, alargar o alcance dos mecanismos tradicionais de salvaguarda dos bens de interesse patrimonial, associando-os a outros instrumentos de promoção da justiça social urbana, já que o direito ao passado e à memória - e mais ainda quando se trata de grupos socialmente vulneráveis - não pode ser dissociado do direito a um presente de dignidade material e de reconhecimento simbólico.

\section{Referências Bibliográficas:}

BAENINGER, Rosana. 1996. Espaço e Tempo em Campinas. Migrantes e a Expansão do Pólo Industrial Paulista. Campinas, Editora da Unicamp.

CHOAY, Françoise. 2009. Le patrimoine en question: anthologie por un combat. Paris: Seuil

2001. A Alegoria do Patrimônio. São Paulo: UNESP

COORDENADORIA Setorial do Patrimônio Cultural. 2011. Ata da Reunião do Conselho de Defesa do Patrimônio Cultural de Campinas $n^{\circ}$ 395. Campinas, Prefeitura de Campinas.

2009. Inventário das Vilas Operárias de Campinas (1930-1960). Fase- I. Relatório de Pesquisa. Campinas, Prefeitura Municipal de Campinas. 
INSTITUTO DO PATRIMÔNIO ARTÍSTICO NACIONAL - IPHAN. 2009. Reflexões sobre a chancela da paisagem cultural brasileira. Brasília: IPHAN

2007. Carta de Bagé ou Carta da Paisagem Cultural. Bagé: IPHAN.

MEIRELLES, Hely Lopes. 2010. Direito Administrativo Brasileiro. São Paulo, Malheiros.

2008. Direito Municipal Brasileiro. São Paulo: Malheiros.

MENEGUELLO, Cristina. FONTES, Paulo e SILVA, Leonardo 2009. "Patrimônio industrial e especulação imobiliária: o caso da Lapa". Vitruvius, Minha Cidade, junho (www.vitruvius.com.br)

FRANCISCO, Rita de Cássia. 2007. As Oficinas da Companhia Mogiana de Estradas de Ferro: arquitetura de um complexo produtivo. Dissertação de Mestrado. São Paulo, USP.

RIBEIRO, Daisy Serra. 2007. Campinas no Estado Novo: Política de Habitação Popular na Formação da Cidade Industrial. Tese de Doutorado. Campinas, UNICAMP.

RODRIGUES, Fabíola. 2008. A Invenção da Cidade: População e Planejamento Urbano, Imaginário e Poder na Formação Urbana de Campinas (1930-2006). Tese de Doutorado. Campinas, UNICAMP.

SANTOS, Milton. 1999. A natureza do espaço. Técnica e tempo, razão e emoção. São Paulo, Hucitec.

SILVA, Josué Pereira. 2008. Trabalho, Cidadania e Reconhecimento. São Paulo, Annablume. 
Para citar essa obra:

RODRIGUES, Fabíola. A patrimonialização do cotidiano: desafio para as políticas públicas.

RUA [online]. 2012, no. 18. Volume 2 - ISSN 1413-2109

Consultada no Portal Labeurb - Revista do Laboratório de Estudos Urbanos do Núcleo de

Desenvolvimento da Criatividade

http://www.labeurb.unicamp.br/rua/

Capa: Autor desconhecido. Estádio Moisés Lucarelli, década de 1950. Disponível em: $<$ http://www.memoriafutebol.com.br/blog/o-majestoso-64-anos>

\author{
Laboratório de Estudos Urbanos - LABEURB \\ Núcleo de Desenvolvimento da Criatividade - NUDECRI \\ Universidade Estadual de Campinas - UNICAMP \\ http://www.labeurb.unicamp.br/ \\ Endereco: \\ LABEURB - LABORATÓRIO DE ESTUDOS URBANOS \\ UNICAMP/COCEN / NUDECRI \\ CAIXA POSTAL 6166 \\ Campinas/SP - Brasil \\ CEP 13083-892 \\ Fone/ Fax: (19) 3521-7900 \\ Contato: http://www.labeurb.unicamp.br/contato
}

